\title{
A preliminary study on post-occupancy evaluation of four office buildings in the UK based on the Analytic Hierarchy Process
}

Article

Accepted Version

Middlehurst, G., Yao, R., Jiang, L., Deng, J., ClementsCroome, D. and Adams, G. (2018) A preliminary study on postoccupancy evaluation of four office buildings in the UK based on the Analytic Hierarchy Process. Intelligent Buildings International Journal, 10 (4). pp. 234-246. ISSN 1750-8975 doi: https://doi.org/10.1080/17508975.2018.1495607 Available at https://centaur.reading.ac.uk/78465/

It is advisable to refer to the publisher's version if you intend to cite from the work. See Guidance on citing.

To link to this article DOI: http://dx.doi.org/10.1080/17508975.2018.1495607

Publisher: Taylor \& Francis

All outputs in CentAUR are protected by Intellectual Property Rights law, including copyright law. Copyright and IPR is retained by the creators or other copyright holders. Terms and conditions for use of this material are defined in the End User Agreement. 


\section{www.reading.ac.uk/centaur}

\section{CentAUR}

Central Archive at the University of Reading

Reading's research outputs online 


\section{A preliminary study on post-occupancy evaluation of four office buildings in the UK based on the Analytic Hierarchy Process}

Gary Middlehurst ${ }^{1,2}$, Runming Yao ${ }^{1, *}$, Lai Jiang $^{1}$, Jie Deng $^{1}$, Derek Clements-Croome ${ }^{1}$, George Adams ${ }^{2}$

1, School of the Built Environment, University of Reading, Chancellors Building, Shinfield Road, Reading, RG6 6AH, UK

2, SPIE UK, 33 Gracechurch St, London EC3V 0BT

* Corresponding author:

Runming Yao

School of the Built Environment, University of Reading, Chancellors Building, Shinfield Road, Reading, RG6 6AH, UK

Tel: +4411833788606

E-mail address: r.yao@reading.ac.uk (R. Yao) 


\section{A preliminary study on post-occupancy evaluation of four office buildings in the UK based on the Analytic Hierarchy Process}

\section{Abstract}

There is a lack of a systematic decision-making criterion to select appropriate indicators for Post-Occupancy Evaluation (POE) analysis due to the fact that significant levels of various POE determinants are indeterminate. The present work aims to identify the degree of importance of a set of POE determinants based on Analytic Hierarchy Process (AHP). A case study of POE for four office buildings in the UK has been conducted using the AHP to ascertain the significance levels of three main factors identified, namely, Indoor Environment Quality (IEQ), Occupants' Performance (OP) and Workplace Quality (WQ) as well as three groups of sub-factors affiliated to the main factors based on questionnaire surveys of the building occupants. The results show that the priority factors of the three main evaluation metrics, IEQ, OP, WQ are $0.595,0.183$ and 0.222 , respectively, indicating that of these three factors the IEQ is the paramount factor in relation to the POE level of the office buildings. Moreover, the global priorities of all sub-factors linked to the main factors are obtained, providing a strategy reference of choosing indicators as per the priorities for a continuing POE in the further survey and measurement.

Keywords: Office evaluation; Post Occupancy Evaluation; Indoor Environment Quality; Occupants feedback; Analytic Hierarchy Process (AHP) 


\section{Introduction}

The UK commercial real estate sector has over many years developed into a complex mixture of integrated relationships with each recognised stakeholder possessing quite different investment and operational needs. With an industry sector essentially controlled and driven by financial investment and return, it is therefore not surprising to see many building projects being focused towards short-term investment, irrespective of occupants' satisfaction and workplace performance in commercial/office buildings. As a matter of fact, paying sufficient attention to the postoccupancy period of existing office buildings by conducting Post-Occupancy Evaluation (POE) is important and indispensable from the perspective of the whole life cycle value of buildings (Vásquez-Hernández and Restrepo Álvarez, 2017; Li et al., 2018), since it will enable the provision of improved strategies for the design, construction and operation of new buildings of the same kind or for building refurbishment. The ultimate intent of POE is to explore higher levels of occupants' satisfaction, performance, health and well-being, consequently contributing to longerterm holistic returns both to the economic investors and society as a whole because occupants staying in an optimum environment tend to be performing more proactively with a high productivity (Agha-Hossein et al, 2013).

The POE is defined as "an appraisal of the degree to which a designed setting satisfies and supports the explicit and implicit human needs and values of those for whom a building is designed" (Friedmann et al., 1978). It is widely accepted that the POE can 
be used as a management tool for providing feedback on building performance, particularly in relation to business efficiency, productivity and the construction industry (Cooper, 2001; Vásquez-Hernández and Restrepo Álvarez, 2017; Clements-Croome, 2018). It is an essential tool to help verify whether these building are performing as intended in the design phase ( $\mathrm{Li}$ et al., 2018). Nevertheless, there is no standardised methodology for POE due to the fact that POE surveys are diverse in terms of subjective intentions of evaluators and, commonly, a variety of methods available (Bordass, 2003; Vásquez-Hernández and Restrepo Álvarez , 2017; Li et al., 2018). Nicol and Roaf (2005) suggested a POE based upon occupant comfort factors but a later research pointed out that assessing POE performance relied upon a number of technical, behavioural and functional elements within the environment being considered (Cutler and Kane, 2009). The latter assumed that technical elements were involved with the building's physical parameters along with Indoor Environment Quality (IEQ) elements such as lighting, temperature, humidity, air quality, etc. Meanwhile, the behavioural elements evaluated occupant satisfaction and whether the building supported the occupants' expectations whilst the functional elements assessed the performances of facilities and hardware in the building.

A recent review on POE published by Li et al. (2018) showed that occupant survey is the most widely used method, presumably because it could help quantify subjective opinions through the use of questions with scaled responses and then benchmark the results. There are lots of such kind of work based on occupant survey in the past two 
decades. Li (1998) assessed the influence of indoor environment on self-reported productivity in offices and claimed that the air quality and pollution are the most important environmental factors related to symptoms of Sick Building Syndrome (SBS) in offices. Seppänen and Fisk (2006) explored some quantitative relations between IEQ and work performance or health, in order to enable building professionals to select building designs and operating practices that accounted for the effects on health and productivity. Frontczak and Wargocki (2011) conducted a survey on indoor environmental conditions influencing comfort in the built environment, such as thermal, visual, acoustic and air quality, in order to determine which of these conditions were ranked by building users as the most important determinants of comfort. They found that thermal comfort is ranked as being of greater importance by building occupants compared to visual and acoustic comfort as well as good air quality. Choi et al. (2012) reckoned that the existing IEQ standards and guidelines were developed without full consideration of the characteristics of the modern building environment, such as gender and age, as well as a work environment equipped with modern technologies, in particular computers and printers. They conducted POEs for 20 office buildings across the U.S. by actual field measurements and user environmental satisfaction surveys over a 7-year period and provided meaningful recommendations and guidance for building environmental designs with a view to enhancing IEQ, improving energy effectiveness and promoting occupant satisfaction, health and productivity. Menezes et al. (2012) reported how knowledge acquired from POE can be used to produce more accurate energy performance models of non-domestic buildings. Kim and Dear (2012) identified 
the nonlinear relationship between individual IEQ factors and occupant overall satisfaction and categorised the IEQ factors into 'basic factors' and 'proportional factors' by adapting and testing Kano's satisfaction model, based on a large number of POE questionnaires in 351 different office buildings with different ventilation types across various climate zones and countries. Agha-Hossein et al. (2013) investigated whether employee 'satisfaction' variables could predict perceived productivity, wellbeing and enjoyment at work and, if so, to what extent. They revealed that the combination of employees' level of satisfaction with 'interior use of space' and 'physical conditions' was the best predictor of their perceived productivity, while satisfaction with 'indoor facilities' was not a good predictor.

Regarding some other methods for POEs, Vásquez-Hernández and Restrepo Álvarez (2017) reviewed the evaluation of buildings in real conditions of use and summarised three types of POE methods based on Preiser (1995) and Turpin-Brooks and Viccars (2006), namely, indicative POE, investigative POE and diagnostic POE. Yao et al. (2008) proposed a holistic approach to evaluate IEQ. The recursive algorithm of the Evidential Reasoning (ER) approach has been used to aggregate multiple indoor environmental indicators, resulting in an aggregated distributed assessment for IEQ. The ER approach is an innovation method which is developed based upon the Dempster-Shafer (DS) theory. One of the advantages of the ER approach is that it is capable of modelling precise data whilst capturing various types of uncertainties as well as the incomplete information. The method was then used to assess the IEQ of a 
building in China (Li and Yao, 2017). Göçer et al. (2015) introduced a new method, the spatial mapping method, for POE to complete the missing link of "building performance feedback" in the building design process. Horr et al. (2016) made a thorough literature survey on the relationship between IEQ and occupant productivity in an office environment and presented a comprehensive discussion and analysis of different IEQ factors that affected occupant productivity. They highlighted eight physical factors that affected IEQ and occupant productivity and argued that thermal comfort, indoor air quality and office layout, as well as noise and acoustics were found to be highly significant in affecting occupant productivity. Bluyssen et al. (2016) developed a procedure to determine associations between characteristics of European offices and the health and comfort of office workers through a checklist and a selfadministered questionnaire including environmental, physiological, psychological and social aspects. They declared that an increase of perceived control over the indoor climate was positively associated with the perceived IEQ. Geng et al. (2017) analysed the effects of the thermal environment on occupant IEQ perception and productivity considering seven groups of experiments in a controlled office environment and using indoor air temperature as the independent variable (varied from $16^{\circ} \mathrm{C}$ to $28^{\circ} \mathrm{C}$ with a step of $2{ }^{\circ} \mathrm{C}$ ). Their results showed that the variation of thermal environment not only affected thermal comfort but also had a "comparative" impact on the perception of other IEQ factors. 
The aforementioned work on the POEs of buildings shows POE results have a close relationship with IEQ, occupants' satisfaction, well-being and productivity and there are a wide range of factors affecting the POE results. For instance, Yao et al. (2008) identified five key factors as indicators for IEQ assessment, namely acoustic, thermal comfort, indoor air quality, visual and electromagnet field. Woon et al. (2015) identified 13 POE critical success factors and 32 sub-factors for the POE of building performance based on a literature review. Candido et al. (2016) introduced the holistic Building Occupants Survey System Australia (BOSSA) project in close collaboration with industry and discussed the statistical analysis used in the BOSSA tool. They distilled the survey results down to nine IEQ dimensions and their association with four overall indices using principal component analysis. The nine uncorrelated IEQ dimensions extracted by them turned out to be spatial comfort, indoor air quality, personal control, noise distraction and privacy, connection to the outdoor environment, building image and maintenance, individual space, thermal comfort and visual comfort.

Nevertheless, it seems there is not a systematic decision-making criterion comprehensively considering physiological and psychological aspects to select appropriate indicators for POE analysis, mainly due to the fact that there are lots of determinants and significant levels amongst different influence factors linked to the POE are indeterminate. It will be interesting to apply some efficient multi-attribute fuzzy evaluation to quantify the degree of importance of various POE aspects. The present work aims to identify the degree of importance of a set of POE determinants 
based on Analytic Hierarchy Process (AHP) (Saaty, 1987; 1990; Liu et al., 2012), which is proved to be an effective method of identifying priorities of building performance (Wong and Li, 2008; ALwaer and Clements-Croome, 2010). Weights of a set of POE determinants in question will be obtained by using the AHP to confirm the priority of various affecting factors of POE for four office buildings in the UK. As argued by Li et al. (2018), a more effective strategy for a continuing POE would be adopting a phased approach to the level-of-detail in the methods by using relatively inexpensive and easy methods to evaluate broad aspects in the first phase and then using those findings to decide which areas of the building or performance issues require further in-depth study in subsequent phases. In this sense, the present work is conducted as a preliminary study of a further POE on the office buildings, since it enables to provide useful strategy reference for organising questionnaire information and investing physical measurement for a continuing POE as per the priority identification of relevant determinants of a preliminary evaluation.

\section{Research Method}

The POE usually relies upon subjective questionnaire surveys completed by building occupants and on-site objective measurements including variables such as indoor air temperature, air humidity, air velocity, lighting, noise, energy consumption, carbon emissions, etc. Due to the complexity and nonquantifiable properties of the factors affecting POE, there are a variety of protocols or tools for building POEs (Li et al., 2018). Usually, the relationships amongst various influence factors of POE are 
ambiguous and it is difficult to discern pivotal factors for POE intuitively. It is therefore necessary to identify the priorities of influence factors of POE from the perspective of a systematic level, as this will help to decide how to effectively organise further questionnaires and invest in-situ measurements with a minimum investment for buildings of the same type. On the other hand, the AHP is proved to be an effective multi-criteria decision-making method for identifying priorities of determinants of a specific system or object. Thus, it is applied to conduct a preliminary POE study on four office buildings in the UK on the basis of questionnaire survey.

\subsection{Analytic hierarchy process}

The AHP method is essentially a multi-criteria decision-making method arranging factors for decision in a hierarchic structure (Saaty, 1987; 1990). Its processing procedures can be summarised into four steps: 1) define the problem; 2) specify the hierarchic structure of decision making; 3) construct the comparison matrices for the analytic hierarchy model; 4) determine the weighting factor of the priorities of all elements (Saaty, 2008). The objective problem is described by a mathematical matrix equation according to the structure of the analytic hierarchy model, while the elements in the matrices that delineate the specific information for the factors are calculated by pairwise comparisons of criteria (or factors). The magnitude of a pairwise comparison indicates how many times one element is more important than another and the values of the elements are scaled from 1 to 9 or their reciprocals, the meaning of which is given 
in Table 1 (Saaty, 2008; Srdevic et al., 2011). Similar judgement scales can be found in previous work (Liu et al., 2012; Ishizaka and Labib, 2009).

Table 1: Magnitudes of the pairwise comparisons (Saaty, 2008; Srdevic et al., 2011)

Once the mathematical matrix equation is constructed aiming at a specific issue by pairwise comparisons of all factors, weighting factors of priorities for the influence factors can be obtained by finding the eigenvector of the matrix (Saaty, 1987). Specifically, assuming $X$ is an n-by-n order matrix correlating the pairwise reciprocal comparisons of relevant factors. The element of matrix $X, x_{i j}$ denotes the comparison between the $i$-row factor and the $j$-column factor, where $i=1,2, \ldots, n$ and $j=1,2, \ldots$, $n$. Here, $n$ equals 9 and according magnitudes are assigned according to Table 1 (Whitaker, 2007). The mathematical matrix equation correlating the eigenvector (i.e. priority vector) $W$ and the maximum eigenvalue $\lambda_{\max }$ is described as in Saaty (2008):

$$
\boldsymbol{X} \boldsymbol{W}=\lambda_{\max } \boldsymbol{W}
$$

The elements of the priority vector $W$ indicate the weighting factors of the priorities of the factors, which stand for the significance level of the factors. 'Saaty's method' introduced in Cabała (2010) is employed in the present study to calculate the priority vector. The method is based on the normalised arithmetic averages and elucidated in the following. Normalise the matrix $X$ to give matrix $R$. The elements $r_{i j}$ of the matrix $R$ at the $i$-row and $j$-column are calculated by: 


$$
r_{i j}=\frac{x_{i j}}{\sum_{i=1}^{n} x_{i j}}
$$

The elements of the eigenvector $\left(w_{i}\right)$ are calculated by:

$$
w_{i}=\frac{\sum_{j=1}^{n} r_{i j}}{n}
$$

The largest eigenvalue of the matrix $\left(\lambda_{\max }\right)$ can be calculated by:

$$
\lambda_{\max }=\frac{1}{n} \sum_{i=1}^{n} \frac{(\boldsymbol{X W})_{i}}{w_{i}}
$$

In the case of multiple factor levels, the calculated $W$ represents local priorities of the sub-factors on the sublayer and their global weighting factors can be calculated by multiplying the local weighting factors with the weighting factors of all its above parent nodes (Tam and Tummala, 2001). A statistical consistency criterion, i.e. consistency rate $(\mathrm{CR})$ is used to judge whether the pairwise reciprocal comparison matrices in the AHP are acceptable or not (Alonso and Lamata, 2006), thus helping to confirm the credibility of data processing. The CR can be calculated using the following equations in terms of the largest eigenvalue $\lambda_{\max }$ (Alonso and Lamata, 2006).

The consistency index $(C I)$ is defined by:

$$
C I=\frac{\lambda_{\max }-n}{n-1}
$$

Then the consistency ratio $(C R)$ can be calculated by:

$$
C R=\frac{C I}{R I}
$$

where the random index (RI) is given by Saaty (1987) as listed in Table 2. The 
consistency of the matrix is acceptable when its $C R<0.1$.

Table 2: Random Index

\subsubsection{Pairwise comparison matrix generating method}

Subjective opinions on one element can be collected using a nine-point Likert scale, then the values of two elements can be converted into pairwise comparisons (Kallas, 2011). Equations (7) and (8) indicate the conversion process. Here $o_{p}$ and $o_{q}$ denote a subjective opinion on the criteria $p$ and criteria $q$ in the Likert scale. If $o_{p}>o_{q}$, the pairwise comparison $o_{p q}$ is given by:

$$
o_{p q}=\left|o_{p}-o_{q}\right|+1
$$

While if $o_{p}<o_{q}$, then $o_{p q}$ is calculated by:

$$
o_{p q}=\frac{1}{\left|o_{p}-o_{q}\right|+1}
$$

\subsubsection{Aggregation of Individual Judgments}

In the present study, the priority of each factor is derived from multiple subjects' opinions. The Aggregation of Individual Judgments (AIJ) method is used to summarise these opinions. The aggregated comparison matrix $\boldsymbol{A}$ is calculated by the geometric mean of all the comparison matrix: $\boldsymbol{X}_{\boldsymbol{t}}$ denotes the comparison matrix from one of the subjects, $t$. The total number of the subjects is $\mathrm{m}$, so $\mathrm{t}=1,2 \ldots, \mathrm{m}$. A detailed explanation of AIJ can be found in Aragon et al. (2012).

$$
A=\sqrt[m]{\prod_{t}^{m} X_{t}}
$$

When the matrix $\boldsymbol{A}$ is determined, the priority factors are calculated from the matrix 
using the method described previously.

2.2 Influence factors of POE for the office buildings

The data on occupants' subjective opinions of building performance with regard to four office buildings in the UK were collected via questionnaire surveys with a total number of 27 subjects. The occupants include persons with specific interests, such as staff, managers, customers or clients, visitors, owners, designers or maintenance teams of the buildings, etc. The four buildings are notated as BS, FP, HP and VE and the distribution of the subjects for each office building is illustrated in Figure 1.

Figure 1: Numbers of subjects selected in each office building

The questionnaire surveys adopted the direct, unmediated experience of building occupants as the basis for evaluating how a building worked for its intended use. The respondents were asked individually to rank the importance of a series of sub-factors linking the POE of relevant buildings using the 9-point Likert scale mentioned in section 2.1.1 for pairwise comparisons, as given in Table 3. A sample question format is described below:

"Within the modern workplace how would you personally rank the importance of the building's HVAC system to recognise my presence and adjust to my pre-set personalised preferred thermal environment?" 
Table 3: Nine-point Likert Scale definition

In the questionnaire surveys of POEs for four office buildings studied in the UK, a total of 109 questions were ranked on the questionnaires but only the questions identified as key factors of the POE are retrieved from the database. The metadata of the survey results is available online as described in the appendix A. The 109 questions in the survey corresponded to the points of the respondents' concern, while the questions related to the three main metrics were selected for a case study. Three metrics IEQ, Occupant Performance (OP) and Workplace Quality (WQ) fully considering physiological and psychological aspects were identified as the main factors linked to a couple of sub-factors individually for the POE. Namely, the factors associated with POE were categorised into a two-tier hierarchy. The key factors assumed are listed in Table 4. Notations $\mathrm{B} i, \mathrm{C} i$ are adopted for convenience in the following. B1, B2, B3 correspond to the main factors, IEQ, OP, WQ, respectively. The first group of subfactors $\mathrm{C} 1$ to $\mathrm{C} 5$ is related to IEQ (B1), while the second group C6-C10 is linked to OP (B2) and the third group C11 to C17 belongs to WQ (B3). The sub-factors of WQ contain the functions of buildings and the facilities in the experimental built environment. As the three main factors IEQ, OP and WQ interact and are intertwined with each other and they jointly affect the POE results of office buildings, it is interesting to explore the significance levels of the factors.

Table 4: Key influence factors of the POE 
2.3 Hierarchic structure of POE for the office buildings and model construction

Figure 2 gives the structure of the analytic hierarchy model for the POE associated with all the key factors identified in Table 4 . The model has three levels counting in the POE aimed to evaluate the workplace and occupants' performance. Overall workplace and occupant performance is noted as A1. The second level corresponds to the three main factors and the third level is constructed by the sub-factors related to each main factor.

Figure 2: Structure of the analytic hierarchy model for the POE

According to the AHP method introduced in section 2.1 and the structure of the analytic hierarchy model in Figure 2, four comparison matrices concerning a group of the main factors and three groups of corresponding sub-factors can be generated based on the questionnaire surveys of relevant subjects. The comparison matrices represent the matrix of the three main factors, the matrix of the IEQ factors, the matrix of the OP factors and the matrix of WQ factors, respectively. Because each subject's opinion regarding the importance of each factor in the database is a magnitude based on the nine-point Likert scale in Table 3, the pairwise comparisons between factors are firstly calculated following Equations (7) and (8). Then they are assigned to the elements of the pairwise comparison matrix. When all the pairwise comparison matrices for the four groups of factors in relation to 27 subjects are calculated, they are combined using the AIJ method illustrated in Equation (9) to generate four aggregated matrices of main factors (B1-IEQ, B2-OP and B3-WQ). With these matrices, Equations (2) to (4) are applied to calculate the local priority factors of each influence factor. 
3 A case study of POE based on the analytic hierarchy process

The survey data of totally 27 subjects in four buildings are lumped to get the priorities of the influence factors identified. Although it is presumed that probably the inherent nature of POE-i.e., that its purpose and associated methods are highly case-dependentmakes it difficult to have a dominant standardized protocol for all the POE projects, one prevailing protocol for one type of buildings is highly possible, especially for residential buildings and office/commercial buildings where most of the research efforts have been devoted ( $\mathrm{Li}$ et al., 2018). In this sense, for buildings of the same type there should be some commonness and it is reasonable to treat 27 subjects collected from four different office buildings in question holistically.

Figure 3 shows the averaged rating scales of respondents in the four buildings versus a set of factors. For the four office buildings in question, the holistic distributions of four buildings tend to be similar, as it is obviously observed that the rating scales for factors C6-C9 are somewhat lower than that of the other factors. Using the original scaled response of the respondents, the pairwise comparison matrices on the two tiers of the hierarchic structure illustrated in Figure 2 are obtained as follows:

(1) Comparison matrix of B1, B2, B3 ( $\mathrm{n}=3)$

$\left[\begin{array}{lll}1.0000 & 3.1812 & 2.7365 \\ 0.3143 & 1.0000 & 0.8108 \\ 0.3654 & 1.2334 & 1.0000\end{array}\right]$

(2) Comparison matrix of $\mathrm{C} 1-\mathrm{C} 5$ 


$\left[\begin{array}{lllll}1.0000 & 2.1748 & 0.7785 & 2.2598 & 1.7507 \\ 0.4598 & 1.0000 & 0.3735 & 1.1200 & 0.8231 \\ 1.2846 & 2.6772 & 1.0000 & 2.7750 & 2.2401 \\ 0.4425 & 0.8928 & 0.3604 & 1.0000 & 0.7587 \\ 0.5712 & 1.2150 & 0.4464 & 1.3180 & 1.0000\end{array}\right]$

(3) Comparison matrix of C6-C10

$\left[\begin{array}{lllll}1.0000 & 0.7395 & 0.7587 & 0.8022 & 0.3167 \\ 1.3523 & 1.0000 & 1.0527 & 1.0733 & 0.3750 \\ 1.3180 & 0.9500 & 1.0000 & 1.0532 & 0.3704 \\ 1.2466 & 0.9317 & 0.9495 & 1.0000 & 0.3506 \\ 3.1580 & 2.6663 & 2.6998 & 2.8523 & 1.0000\end{array}\right]$

(4) Comparison matrix of $\mathrm{C} 11-\mathrm{C} 17$

$\left[\begin{array}{ccccccc}1.0000 & 1.4669 & 3.0590 & 1.1370 & 1.3122 & 1.6734 & 1.6479 \\ 0.6817 & 1.0000 & 2.3423 & 0.7669 & 0.8757 & 1.2704 & 1.1404 \\ 0.3269 & 0.4269 & 1.0000 & 0.3624 & 0.4189 & 0.5676 & 0.5687 \\ 0.8795 & 1.3040 & 2.7592 & 1.0000 & 1.1414 & 1.5242 & 1.5502 \\ 0.7621 & 1.1419 & 2.3870 & 0.8761 & 1.0000 & 1.3438 & 1.3543 \\ 0.5976 & 0.7872 & 1.7618 & 0.6561 & 0.7442 & 1.0000 & 0.9472 \\ 0.6068 & 0.8769 & 1.7583 & 0.6451 & 0.7384 & 1.0557 & 1.0000\end{array}\right]$

Based on the pairwise comparison matrices generated and the processing method described previously, the calculated weight factors are obtained, as given in Figure 4. It can be seen that on level two the IEQ (B1) has the highest priority factor of 0.595 compared to the other two main factors OP (B1) and WQ (B3), indicating that of the three main factors the IEQ is the paramount factor in relation to the POE level of the office buildings. It is meant that IEQ should be paid more attention to than the other two factors OP and WQ in the further phase of a continuing POE. The effects of factors OP and WQ are 0.183 and 0.222 , respectively. 
Figure 3: Averaged rating scales of respondents in the four buildings versus factors

Figure 4: Local priority factors of the hierarchic structure for the POE

For the group of sub-factors affiliated to the IEQ, the sub-factor with the highest weighting factor is C3 (Thermal Quality), followed by C1 (Lighting Quality) with the second highest weighting factor. Regarding the group links to the OP, the sub-factor C10 (Understanding occupant activity levels within the workplace to avoid a sedentary existence) has the highest weighting factor of 0.414 . When it comes to the group of WQ factors, the most important sub-factor is C11 (Sufficient work space so as not to feel over-crowded). It is also noteworthy that the least important sub-factor in the group is C13 (Transition from outside the building to desk as easily as possible).

Besides, the CR values of the pairwise comparison matrices calculated by Equations (5) and (6) are depicted in Figure 5. It suggests that the CR values are all smaller than 0.1, meaning that the consistency levels of the pairwise comparison matrices are acceptable and the data analysis is convincing.

Figure 5: The consistency ratio of the pairwise comparison matrices

To further ascertain the importance levels of all the sub-factors related to the three main factors from the perspective of global comparison, the global weighting factors are calculated by the local weighting factors of the hierarchic structure in Figure 4. The 
result is listed in Table 5. It can be found that among all the sub-factors, C3 (Thermal Quality) has the highest weighting factor (0.201), followed by C1 (Lighting Quality) with a weighting factor of 0.159 . The global weighting factors of the others are below 0.1. This indicates that thermal quality and lighting quality are the two most significant sub-factors amongst all the sub-factors. Besides, the weight of C13 (Transition from outside the building to desk as easily as possible) is the smallest. The global weighting factors represent corresponding priorities of relevant influence factors, it will provide useful reference for organising questionnaire survey and investing physical measurement in the further development of POE.

Table 5: The global priority weights of all factors concerned

\section{Conclusions}

AHP is applied to quantify the degree of importance (indicated by the global weighting factors) of various determinants of POE combining the survey results of four office buildings in the UK. Indoor Environment Quality (IEQ), Occupants' Performance (OP) and Workplace Quality (WQ) are identified as the three main factors affecting POE results fully considering physiological and psychological aspects. And three groups of sub-factors linked to the main factors are categorized to construct the analytic hierarchy model. Questionnaire surveys on occupants' objective opinions of four office buildings in the UK have been collected and adopted to specify the analytic hierarchy model as a case study. It is found that the priority factors of the three main evaluation metrics, IEQ, OP, WQ are $0.595,0.183$ and 0.222 , respectively, indicating that of the three factors 
the IEQ is the paramount factor in relation to the POE level of the office buildings and should be paid more attention to. Regarding the global priorities of all the sub-factors linked to the main factors, thermal quality and lighting quality are identified as the two most significant sub-factors according to the evaluation results. When it comes to the OP factor, it is found that "occupants' activity level within the workplace to avoid a sedentary existence" is the most pivotal factor to be monitored. The most significant sub-factor concerning WQ turns out to be "Sufficient work space so as not to feel overcrowded". The work can be assumed as a preliminary study of the POE for the office buildings, since the global priorities of POE determinants will provide indicators for designing questionnaire and investing physical measurements for further work of a continuing POE.

\section{Appendix A. Supplementary material}

The metadata of the questionnaire survey used for the case study of the POE are openly available from the University of Reading Research Data Archive at: http://dx.doi.org/10.17864/1947.138.

\section{References}

Agha-Hossein, M.M.A., El-Jouzi, S. Elmualim, A.A., Ellis, J. and Williams, M. 2013. "Post-occupancy studies of an office environment: Energy performance and 
occupants' satisfaction.” Building and Environment 69: 121-130.

Alonso, J.A. and Lamata, M.T. 2006. "Consistency in the analytic hierarchy process: a new approach." International journal of uncertainty, fuzziness and knowledgebased systems 14: 445-459.

ALwaer, H.,Clements-Croome, D.J. 2010. "Key performance indicators (KPIs) and priority setting in using the multi-attribute approach for assessing sustainable intelligent buildings." Building and Environment 45(4): 799-807.

Bordass, B. 2003. "Learning more from our buildings - or just forgetting less?” Building Research and Information 31: 406-411.

Cabala, P. 2010. "Using the analytic hierarchy process in evaluating decision alternatives." Operations research and decisions 20: 5-23.

Candido, C., Kim, J., Dear, R.D. and Thomas, L. 2016. "BOSSA: a multidimensional post-occupancy evaluation tool.” Building Research \& Information 44 (2): 214228.

Choi, J.-H., Loftness, V. and Aziz, A. 2012. "Post-occupancy evaluation of 20 office buildings as basis for future IEQ standards and guidelines." Energy and Buildings 
46: $167-175$.

Clements-Croome, D. J., ed. 2018. "Creating the productive workplace: places to work creatively, Chapters 1 and 2.” Routledge, London. ISBN 9781138963344.

Cooper, I. 2001. "Post-occupancy evaluation-where are you?" Building Research \& Information 29: 158-163.

Cutler, L.J., and Kane, R.A. 2009. "Post-occupancy evaluation of a transformed nursing home: the first four Green House ${ }^{\circledR}$ settings.” Journal of Housing for the Elderly 23(4): 304-334.

Friedmann, A., Zimring, C. and Zube, E.H. 1978. Environmental design evaluation, New York: London, Plenum Press.

Frontczak, M. and Wargocki, P. 2011. "Literature survey on how different factors influence human comfort in indoor environments." Building and Environment 46: 922-937.

Geng, Y., Ji, W., Lin, B. and Zhu, Y. 2017. "The impact of thermal environment on occupant IEQ perception and productivity.” Building and Environment 121: 158167. 
Göçer, Ö., Hua, Y. and Göçer, K. 2015. “Completing the missing link in building design process: Enhancing post-occupancy evaluation method for effective feedback for building performance.” Building and Environment 89: 14-27.

Horr, Y.A., Arif, M., Kaushik, A., Mazroei, A., Katafygiotou, M. and Elsarrag, E. 2016. "Occupant productivity and office indoor environment quality: A review of the literature.” Building and Environment 105: 369-389.

Ishizaka, A. and Labib, A. 2009. "Analytic hierarchy process and expert choice: Benefits and limitations." Or Insight 22 (4): 201-220.

Kallas, Z. 2011. Butchers' preferences for rabbit meat; AHP Pairwise comparisons versus a LIKERT scale valuation. Proceedings of the International Symposium on the Analytic Hierarchy Process for Multicriteria Decision Making, pp 1-6.

Kim, J. and Dear, R.D. 2012. "Nonlinear relationships between individual IEQ factors and overall workspace satisfaction." Building and Environment 49:33-40.

Kim, J. Dear, R.D., Cândido, C., Zhang, H., Arens, E. 2013“Gender differences in office occupant perception of indoor environmental quality (IEQ).” Building and Environment 70: 245-256. 
Li B. 1998. "Assessing the influence of indoor environment on self-reported productivity in offices." Doctor of Philosophy, Department of Construction Management and Engineering, University of Reading, Reading, UK.

Li,P., Froese, T.M., Brager, G. 2018. "Post-occupancy evaluation: State-of-the-art analysis and state-of-the-practice review." Building and Environment 133: 187202.

Liu, J., Yao, R. and McCloy, R. 2012. "A method to weight three categories of adaptive thermal comfort." Energy and Buildings 47: 312-320.

Menezes, A.C., Cripps, A., Bouchlaghem, D. and Buswell, R. 2012. "Predicted vs. actual energy performance of non-domestic buildings: Using post-occupancy evaluation data to reduce the performance gap.” Applied Energy 97: 355-364.

Nicol, F. and Roaf, S. 2005. "Post-occupancy evaluation and field studies of thermal comfort.” Building Research \& Information 33: 338-346.

Saaty, R. W. 1987. "The analytic hierarchy process - what it is and how it is used." Mathematical Modelling 9: 161-176. 
Saaty, T. L. 1990. "How to Make a Decision - the Analytic Hierarchy Process." European Journal of Operational Research 48: 9-26.

Saaty, T. L. 2008. "Decision making with the analytic hierarchy process." International journal of services sciences 1: 83-98.

Li, B. and Yao, R. 2017. “Chapter 4: Indoor Environment and Assessment. In: Sayigh, A., Ed. Sustainable High Rise Buildings in Urban Zones: Advantages, Challenges, and Global Case Studies.” Springer International Publishing, Switzerland: 79-92.

Preiser, W.F.E. 1995. "Post-occupancy evaluation: how to make buildings work better." Facilities, Vol. 13 (11):19-28.

Seppänen, O.A. and Fisk, W. 2006. "Some quantitative relations between indoor environmental quality and work performance or health." HVAC\&R Research 12(4): 957-973.

Srdevic, Z., Blagojevic, B. and Srdevic, B. 2011. "AHP based group decision making in ranking loan applicants for purchasing irrigation equipment: a case study." Bulgarian Journal of Agricultural Science 17: 531-543. 
Tam, M.C.Y. and Tummala, V.M.R. 2001. "An application of the AHP in vendor selection of a telecommunications system." Omega-International Journal of Management Science 29: 171-182.

Turpin-Brooks, S. and Viccars, G. 2006. “The development of robust methods of post occupancy evaluation.” Facilities 24: 177-196.

Vásquez-Hernández, A. and Restrepo Álvarez M.F. 2017. "Evaluation of buildings in real conditions of use: Current situation.” Journal of Building Engineering 12: 2636.

Whitaker, R. 2007. "Validation examples of the analytic hierarchy process and analytic network process." Mathematical and Computer Modelling 46: 840-859.

Woon, N.B., Mohammad, I.S., Baba, M., Zainol, N.N., and Nazri, A.Q. 2015. “Critical Success Factors for Post Occupancy Evaluation of Building Performance: A Literature Analysis.” Jurnal Teknologi (Sciences \& Engineering) 74 (2): 41-49.

Wong, J. K.W., Li,H. 2008. “Application of the analytic hierarchy process (AHP) in multi-criteria analysis of the selection of intelligent building systems." Building and Environment 43(1): 108-125.

Yao, R., Yang, Y. and Li, B. 2008. “A method of assessing indoor environment quality 
using an evidential reasoning approach. In: The proceedings of the $10^{\text {th }}$ World Renewable Energy Congress.” Glasgow, Scotland, pp.19-25. 


\section{Table Captions:}

Table 1: Magnitudes of the pairwise comparisons (Saaty, 2008; Srdevic et al., 2011)

Table 2: Random Index

Table 3: Nine-point Likert Scale definition

Table 4: Key factors of the POE

Table 5: The global priority weights of all factors concerned

\section{Figure Captions:}

Figure 1: Numbers of subjects selected in each office building

Figure 2: Structure of the analytic hierarchy model for the POE

Figure 3: Averaged rating scales of respondents in the four buildings versus factors

Figure 4: Local priority factors of the hierarchic structure for the POE

Figure 5: The consistency ratio of the pairwise comparison matrices 